\title{
THE SATISFACTION OF OLDER ADULTS ABOUT ONLINE GROUP EXERCISE PROGRAM: AN ALTERNATIVE OPTION TO MAINTAIN PHYSICAL AND MENTAL WELLBEING DURING COVID 19 PANDEMIC
}

\section{---Are older adults satisfied with online group exercise program?}

\author{
Mayur Revadkar, Riddhi Goradia \\ Dept. of Community Physiotherapy, K J Somaiya College of Physiotherapy, India
}

Correspondence:mayur.kr@somaiya.edu

\section{ABSTRACT}

\section{BACKGROUND:}

Considering the impact of lockdown on older adults, there is a need for some online option to maintain the physical and mental well-being of this vulnerable population in the current pandemic situation. Generally, In the Indian context, elderly are not well acquainted with online platforms for different purposes of shopping, health or for being socially active. However with adequate training they are willing to learn new technologies and adapt to online platforms.

OBJECTIVES:

To find the satisfaction of Online group exercise program for older adult's population to maintain their physical and mental well-being.

\section{METHODOLOGY:}

It was a web-based intervention study where 40 participants were invited to fill the patient satisfaction questionnaire and feedback form using Google Forms. Participants who have attended the online group exercise class at least for a period of 1 month (20 Sessions) were included in the study. Out of 40,34 participants responded to the questionnaire.

RESULTS:

As per descriptive statistical analysis, results showed that $100 \%$ of study population was satisfied in all aspects of online exercise program.

\section{CONCLUSION:}

With adequate training and constant technical support; elderly population can be encouraged to participate in online group exercise program which is well appreciated by this population as an alternative option in changing health care deliverymodels.

\section{KEYWORDS}

Older adults, COVID 19 pandemic, Online Exercise. 
INTRODUCTION

The world had to face a biological crisis in the form of COVID 19 pandemic; leading to major changes in delivering health care services which were shifted from offline to online mode. It has affected the older adults differently than the younger generation. Lockdown has put restrictions on everyone's social life and especially the older adults being a vulnerable population are significantly affected. It has reduced their outside physical activity and they are more dependent on their family members. It affected their mental health too. [1]

Reduced physical activity is associated with increased rate of mortality, developing chronic health conditions in older adult populations. [2] Therefore it is important to create some opportunities for their healthy ageing considering the impact of the COVID 19 pandemic on their physical and mental health.

Dr. Martin from the University of Aberdeen stated that prolonged home confinement and reduced physical activity can increase the frailty in the older adults population; thus increasing their morbidity and mortality rate. [3]

To overcome geographical barriers and increase access to healthcare services; Telemedicine is used as a key which incorporates information and communication technologies (ICT's). It has been in practice in different parts of the world since 1990; but COVID 19 pandemic has led to emergence of telemedicine in almost all parts of the globe. Telerehabilitation is considered as a branch of telemedicine. $[4,5]$

Considering the impact of lockdown on older adults, there is a need for some online option to maintain the physical and mental well-being of this vulnerable population in the current pandemic situation. Generally, In the Indian context, older adults are not well acquainted with online platforms for different purposes of shopping, health or for being socially active. However with adequate training they are able to learn new technologies and adapt to online platforms. $[6,7,8]$

Studies have shown that telemedicine is feasible and allows medical professionals to continue providing outpatient services with a high level of patient satisfaction. During the current pandemic, this experience can provide a viable alternative for many outpatient services while reducing the need for travel and face-to-face contact to a minimum. $[9,10]$ The key barrier identified for telemedicine was technical issues. [1 1]

A systematic review revealed that there is high patient satisfaction with telerehabilitation services. The success of telehealth as a service delivery model was attributed to quality of care, safety, reduced cost and no travelling. [12] In the current suboptimal pandemic climate, virtual geriatric clinics may allow Geriatricians to continue to provide an outpatient service, despite the encountered inherent challenges. [13]

Leif Bob et al concluded that the Client Satisfaction Questionnaire having an overall good psychometric property can be used as an outcome measure for evaluating the effectiveness of telemedicine interventions. [14] As the healthcare industry is growing; its focus is moving on client satisfaction. Hospital administrators are focusing on patient satisfaction about all aspects of health care delivery and it's one of the quality benchmarks.[15]

Therefore, we devised the structured online exercise program for our senior citizens (SAFE Class - Senior Adult Fitness E Class) which focused on physiological changes of ageing happening in their bodies and their needs. It becomes challenging to consider the performance-based outcome measures for evaluating the efficacy of such interventions in online mode, and patient-reported outcomes measures such as patient satisfaction surveys which has shown good reliability and validity for evaluating web-based interventions. [3] Therefore, the present study focuses on promoting health of an older adults using telerehabilitation and finding users satisfaction of structured online exercise program by using the patient satisfaction survey and structured feedback form.

OBJECTIVES: To find the efficacy of the Online Exercise Program for the older adult's population to maintain their physical and mental well-being using the Patient Satisfaction Questionnaire and Structured Feedback form.

OPERATIONAL DEFINITION: Older Adult: Anyone whose age is more than 50 years on the day of participation. [16]

METHODOLOGY: It was a web-based intervention study where 40 participants were invited to fill the patient satisfaction questionnaire and feedback form using 
Google Forms. Participants who have attended the online group exercise class at least for a period of 1 month (20 Sessions) were included in the study. Out of 40, 34 participants responded to the questionnaire.

\section{The structured Online Exercise Program was as} follow:

1. Participants were provided with zoom details for an online class, and they were also provided with technical assistance if any to join the exercise program on the zoom platform.

2. The exercise program was planned for five days a week for 45 minutes duration. Each session is preceded by a warm-up and concluded with a cool down.

3. Exercises were planned based on the review of literature which includes aerobic exercises, strengthening exercises, Balance training, Mat Exercises with frequency and intensity comfortable to the older adults population at large.

4. Over and above this, Participants were encouraged to participate in Small Group Meetings (SGM) and Individualized sessions for any specific health issues which can be addressed by physical therapy interventions, so as to increase the functional independence of participants. SGM was conducted twice a month and Individualized sessions were conducted four times a month.

5. The Patient Satisfaction Questionnaire was formulated based on our intervention program and a review of the literature.

6. Also, all participants were asked to fill up one structured feedback form for a qualitative assessment of the exercise program.

\section{DEVELOPMENT OF THE QUESTIONNAIRE}

Patient satisfaction is one the important indicators of success of any health care intervention. It helps to deliver patient centered care and can be an indicator for improving the quality of the program. A systematic review done for validated patient satisfaction measurement instruments showed that patient satisfaction is a multidimensional construct and it shall essentially include aspects such as patient and professional interaction, physical environment and internal management processes. While designing the online group exercise program, patient centered care was kept at focus and older adults person's preferences about decision making in their care were taken into consideration. [3]
A rheumatism research unit of the University of Leeds developed a patient satisfaction questionnaire to assess the care received in the rheumatology outpatient clinic (1992, Hill J et al). The present study has used the framework of this questionnaire to formulate the patient satisfaction questionnaire in the current study. [17]

The patient satisfaction questionnaire was developed to measure the satisfaction of online exercise programmes amongst patients attending SAFE Class. It was a selfadministered questionnaire with patients answering their level of agreement with a series of 45 statements. Possible responses were recorded on a scale ranging from 1 to 5; where 1 stands for strongly agree and 5 stands for strongly disagree. The questionnaire included statements with different aspects of online exercise program, such as:
A. General Satisfaction
B. Giving of Information
C. Empathy with Patient
D. Technical Quality and Competence
E. Attitude towards patient
F. Access and Continuity

In order to minimize bias, statements were expressed in both positive and negative sentiments and were presented in random order. Also, a total score was taken into consideration to provide a measure of overall satisfaction.

\section{ANALYSIS OF THE QUESTIONNAIRE INVOLVED THE FOLLOWING STEPS}

A. As the questions were put in random order, they were initially sorted into different aspects of care such as Group A: General Satisfaction, Group B: Giving information and so on.

B. Also, questions were framed with positive and negative sentiments; therefore for analysis recording was done so that all scores are in the same "sense" i.e. a high score always indicates a level of satisfaction. All positive statements were recoded as 6 minus the actual score.

C. Further, scores for all questions under one group were combined and an average was taken to arrive at a normalized score for a particular group.

D. Lastly, all scores were combined to arrive at a figure for overall satisfaction. 
The analysis provided a score out of 5 for each aspect of care. Scores above 3 indicate satisfaction \& below 3 indicates dis-satisfaction.

The questionnaire was developed in the English language and later translated into Hindi for participants who were not comprehensive towards English. Face validity was done for both questionnaires.

\section{RESULTS}

As per descriptive statistical analysis, results showed that $100 \%$ of the study population was satisfied in all aspects of the online exercise program (Mean Score more than 3). All participants opined that this online exercise program has helped them to improve their physical and mental fitness.

TABLE 1: DEMOGRAPHIC TABLE

\section{Demographic Table}

\begin{tabular}{|l|l|l|}
\hline Details & Mean & SD \\
\hline Age (in years) & 61 & 6.82 \\
\hline & Males: 1 \\
Gender & Females: 33 \\
\hline
\end{tabular}

\section{GRAPH 1: OVERALL SATISFACTION}

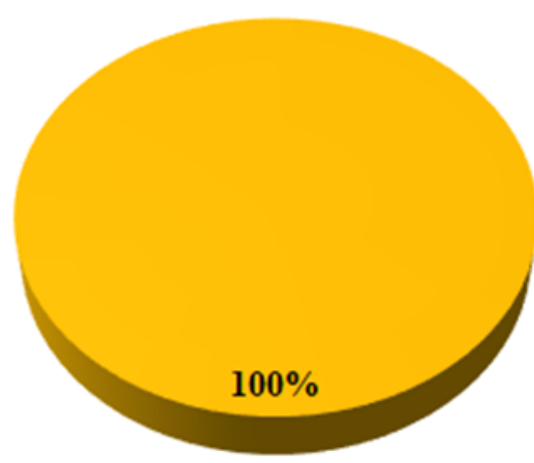

\#verall Satisfaction

GRAPH 2: DIFFERENT ASPECTS OF PATIENT SATISFACTION

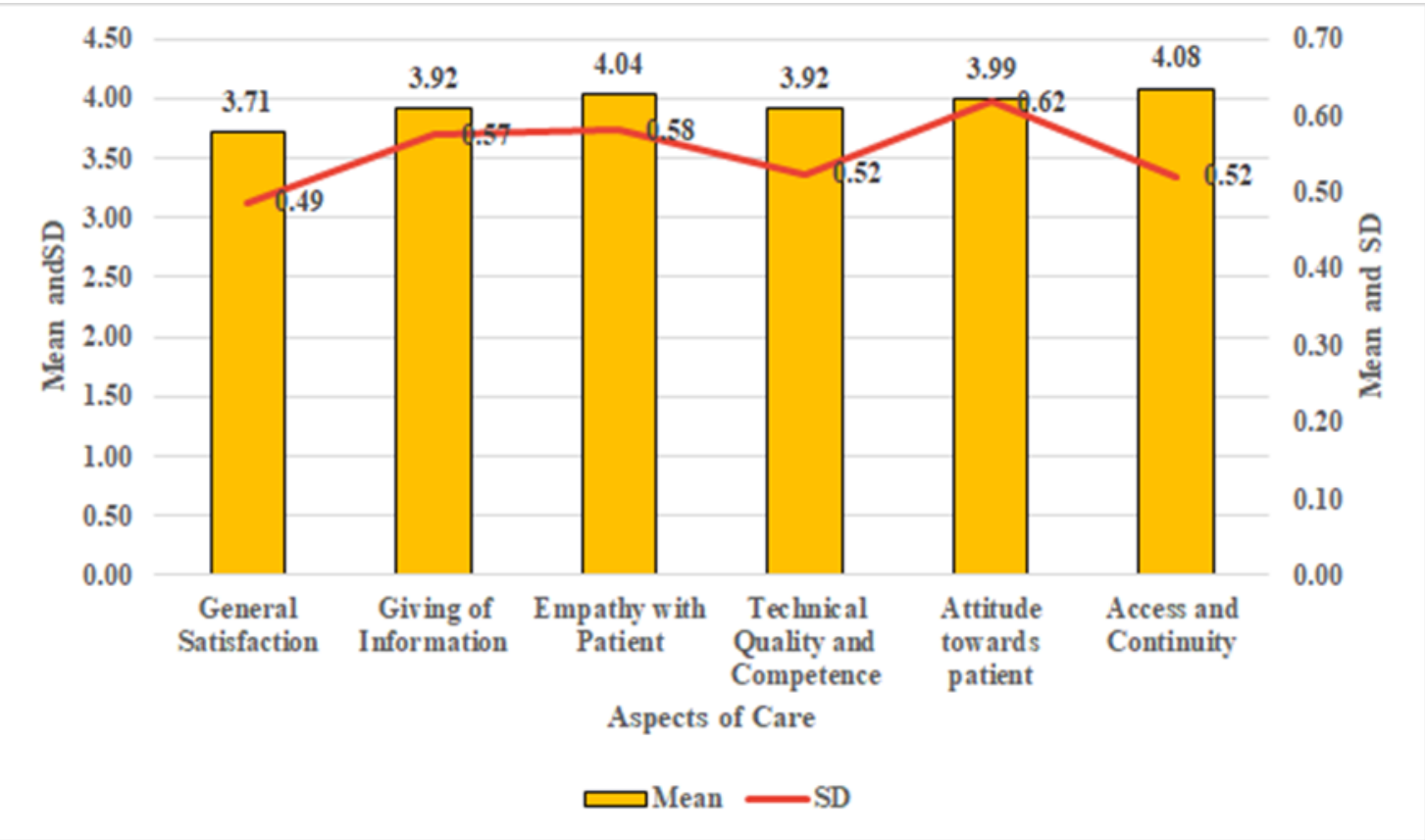




\begin{tabular}{|c|c|c|c|}
\hline & YES & NO & $\begin{array}{l}\text { NOT } \\
\text { SURE }\end{array}$ \\
\hline $\begin{array}{l}\text { Do you feel physically fit after participating in a structured online group exercise } \\
\text { program? }\end{array}$ & $85 \%$ & $6 \%$ & $9 \%$ \\
\hline $\begin{array}{l}\text { Do you feel mentally fit after participating in a structured online group exercise } \\
\text { program? }\end{array}$ & $82 \%$ & $12 \%$ & $6 \%$ \\
\hline $\begin{array}{l}\text { Between the two, what would be your preferred option for participating in a } \\
\text { physical fitness exercise program? (Online: Exercising via Video Call under the } \\
\text { supervision of Physiotherapist; Offline: Visiting a particular physiotherapy or health } \\
\text { center in person) }\end{array}$ & \multicolumn{3}{|c|}{ Online: $88 \%$} \\
\hline
\end{tabular}

\section{DISCUSSION}

Present study evaluated effectiveness of an online group exercise program for older adult's population using a patient satisfaction questionnaire and structured feedback form. It was observed that all patients were satisfied with the conduction of an online group exercise program, and they perceived it helped them to maintain physical and mental fitness.

Indian older adults are accustomed to do physical exercises under supervision in groups at fitness centers in offline mode; however, the current pandemic situation made them home confined. This affected their physical activity and social interactions; indirectly affecting mental health. Therefore, we thought of providing an online group exercise program as an alternative to remain physically active.

Patient satisfaction can be considered as one of the measures of quality of health care delivery system. Also, patient satisfaction can be directly related with his/her compliance towards therapy. We assessed satisfaction of patients about different aspects of online group exercise programs using 5 points likert scale. The questionnaire included statements with different aspects of online exercise program, such as: General Satisfaction, Giving of Information, Empathy with Patient, Technical Quality and Competence, Attitude towards patient, Access and Continuity

We attribute the success of this online program to below points.
1. Before joining the exercise program, participants' history and health related information was noted using Google form and they were screened for eligibility to join the group exercise program.

2. A WhatsApp group was formed for ease of communication with all participants. Participants were provided with adequate training if needed to use the zoom platform to access the online exercise program.

3. Adequate and appropriate information was given to the participants about the exercise program; benefits of various exercises, do's and don'ts of exercise.

4. We trained a team of therapists to execute this online group exercise program. They were also responsible for individual assessment of respective patients and addressing their individual needs.

5. Participants were requested to keep their video on for the supervision of exercises and they were instructed to correct the form of exercise if need be.

6. Over and above Group exercise we also conducted small group meetings twice a month; where, participants could address their health issues to us and they were provided with appropriate advice or home exercise program during their individual sessions which was conducted once a week

Current study findings are consistent with systematic review done in 2019. They proposed that telehealth appears to enhance communication and engagement between health care providers and patients and their caregivers, especially through real-time videoconferencing. Irrespective of information and communication technologies, consumer focus remains a critical aspect of how a service was delivered. $[18,19]$ 
Online mode of exercises or telerehabilitation can be beneficial to the one who is confined to the home and does not have assistance or health care services are not easily accessible. It also saves travel time and cost. However; there can be some barriers as not being able to evaluate the patients physically and absenteeism of physical supervision can lead to injuries. As a future scope of study, efficacy of online exercise programs in terms of outcome measures such as pain, function etc can be studied.

\section{CONCLUSION}

With adequate training and constant technical support; older adult population can be encouraged to participate in an online exercise program which is well appreciated by this population as an alternative option in changing health care delivery models. Patient Reported Outcome measures can be included by Healthcare Managers to evaluate the success and Quality of health care.

Present study suggest that online group exercise program for older adults can also be satisfactory mode of exercise prescription and it should focus on various aspects of care such as Technical Quality and Competence, giving appropriate information and empathy towards older adults.

\section{ACKNOWLEDGMENT:}

We are thankful to Dr. Shweta Manwadkar, Principal, K J Soamiya College of Physiotherapy for her constant support and encouragement in execution of telerehabilation program for older adults.

We are grateful to Ms. Kritika Jain and her team from $\mathrm{K} J$ Somaiya Institute of Management Studies and Research for processing and coordinating our manuscript with Asia Pacific Journal of Health Management.

We are thankful to team of physiotherapist who worked with us in execution of this online exercise program.

Furhter, we are thankful to all participants who participated in this research.
1. Steinman MA, Perry L, Perissinotto CM. Meeting the care needs of older adults isolated at home during the COVID-19 pandemic. JAMA internal medicine. 2020 Jun $1 ; 180(6): 819-20$.

2. Taylor D. Physical activity is medicine for older adults. Postgraduate medical journal. 2014 Jan 1;90(1059):2632.

3. Almeida RS, Bourliataux-Lajoinie S, Martins M. Satisfaction measurement instruments for healthcare service users: a systematic review. Cadernos de saudepublica. 2015;31:11-25.

4. World Health Organization. Telemedicine: opportunities and developments in member states. Report on the second global survey on eHealth. World Health Organization; 2010.

5. Peretti A, Amenta F, Tayebati SK, Nittari G, Mahdi SS. Telerehabilitation: review of the state-of-the-art and areas of application. JMIR rehabilitation and assistive technologies. 2017;4(2):e7.

6. How India's elderly population unleashes the powers of new-age technology [Internet]. The Indian Express. 2021 [cited 20 March 2021]. Available from: https://indianexpress.com/article/lifestyle/lifestyle/india-elderly-population-elders-powers-of-newage-technology-6912305/

7. Ghosh M. Analysing the Engagement and Attitude of elderly Towards Digital Platforms in India. Journal of Creative Communications. 2019 Nov;14(3):214-34.

8. Older adults Empowerment in the Digital Age [Internet]. HalpAge India. 2021 [cited 20 March 2021]. Available from: https://www.helpageindia.org/older adults-empowerment-in-the-digital-age-2/

9. Negrini S, Donzelli S, Negrini A, Negrini A, Romano M, Zaina F. Feasibility and acceptability of telemedicine to substitute outpatient rehabilitation services in the COVID-19 emergency in Italy: an observational everyday clinical-life study. Archives of physical medicine and rehabilitation. 2020 Nov 1;101 (1 1):202732.

10. Buchalter DB, Moses MJ, Azad A, Kirby DJ, Huang S, Bosco III JA, Yang SS. Patient and Surgeon Satisfaction with Telehealth During the COVID-19 Pandemic.

Bulletin of the NYU Hospital for Joint Diseases. 2020 Oct $1 ; 78(4): 227-35$.

11. Tenforde AS, laccarino MA, Borgstrom H, Hefner JE, Silver J, Ahmed M, Babu AN, Blauwet CA, Elson L, Eng C, Kotler D. Feasibility and high quality measured in

\section{References:}

The satisfaction of older adults about Online Group Exercise Program: an alternative option to maintain physical and mental wellbeing during COVID 19 
the rapid expansion of telemedicine during COVID-19 for sports and musculoskeletal medicine practice. $\mathrm{Pm}$ \& R. 2020 May 18.

12. Harkey LC, Jung SM, Newton ER, Patterson A. Patient Satisfaction with Telehealth in Rural Settings: A Systematic Review. International Journal of Telerehabilitation. 2020 Dec 8;12(2):53-64.

13. Murphy RP, Dennehy KA, Costello MM, Murphy EP, Judge CS, O'Donnell MJ, Canavan MD. Virtual geriatric clinics and the COVID-19 catalyst: a rapid review. Age and ageing. 2020 Nov;49(6):907-14.

14. Boß L, Lehr D, Reis D, Vis C, Riper H, Berking M, Ebert DD. Reliability and validity of assessing user satisfaction with web-based health interventions. Journal of medical Internet research. 2016;18(8):e234.

15. Al-Abri R, Al-Balushi A. Patient satisfaction survey as a tool towards quality improvement. Oman medical journal. 2014 Jan;29(1):3.

16. International Institute for Population Sciences (IIPS), National Programme for Health Care of Elderly (NPHCE), MoHFW, Harvard T. H. Chan School of Public Health (HSPH) and the University of Southern California (USC) 2020. Longitudinal Ageing Study in India (LASI) Wave 1, 2017-18, India Report, International Institute for Population Sciences, Mumbai.

17. Hill J, Bird HA, Hopkins R, Lawton C, Wright V. Survey of satisfaction with care in a rheumatology outpatient clinic. Annals of the rheumatic diseases. 1992 Feb; 51 (2):195-7.

18. Dana Principe SP, Gabrielle Pierce SP, Tracey Collins PT. Patient Satisfaction in Older Adults using Telerehabilitation in Home Health: A Systematic Review

19. Orlando JF, Beard M, Kumar S. Systematic review of patient and caregivers' satisfaction with telehealth videoconferencing as a mode of service deliveryin managing patients' health. 2019;14(8) 